\title{
PROSPECTIVE STUDY OF PATHOGENS ASSOCIATED WITH COMMUNITY ACQUIRED PNEUMONIA IN A MIXED POPULATION OF HIV AND NON-HIV INFECTED ADULTS
}

\author{
P. V. Kalyan Kumar1, Ramakrishna Gorantlaㄹ, Ramakrishna Rachakonda ${ }^{3}$, Kolla Sravini ${ }^{4}$, Venu $M^{5}$, Nageswara Rao G6 Indira $D^{7}$ \\ ${ }^{1}$ Associate Professor, Department of Pulmonary Medicine, Katuri Medical College \& Hospital, Guntur, Andhra Pradesh. \\ ${ }^{2}$ Assistant Professor, Department of General Medicine, Katuri Medical College \& Hospital, Guntur, Andhra Pradesh. \\ 3 Professor \& HOD, Department of Pulmonary Medicine, Katuri Medical College \& Hospital, Guntur, Andhra Pradesh. \\ ${ }^{4}$ Senior Resident, Department of Paediatrics, Katuri Medical College \& Hospital, Guntur, Andhra Pradesh. \\ ${ }^{5}$ Assistant Professor, Department of Pulmonary Medicine, Katuri Medical College \& Hospital, Guntur, Andhra Pradesh. \\ ${ }^{6}$ Assistant Professor, Department of Pulmonary Medicine, Katuri Medical College \& Hospital, Guntur, Andhra Pradesh. \\ ${ }^{7}$ Senior Resident, Department of General Medicine, Katuri Medical College \& Hospital, Guntur, Andhra Pradesh.
}

ABSTRACT

\begin{abstract}
AIM OF STUDY
To determine the pathogens of Community Acquired Pneumonia (CAP) in HIV and non-HIV infected adults admitted to tertiary health centre in Guntur, Andhra Pradesh, India.
\end{abstract}

\section{MATERIALS AND METHODS}

Patients diagnosed of CAP between March 2014 and July 2015 were studied. The study was prospective. Samples of sputum, blood, serum, pleural fluid, urine and bronchoalveolar lavage fluid where applicable were collected for microbiological testing.

\section{RESULTS}

A total of 240 patients, mean age 33 years, range 18-82 years were enrolled; 92 of the 240 patients tested (38\%) were HIV infected. Pathogens for CAP were isolated in 129 patients (53\%). The commonest organisms were Mycobacterium Tuberculosis (41\%) followed by Mycoplasma pneumoniae (29\%), Streptococcus Pneumonia (26\%) and Pneumocystis Pneumonia (PCP) (7\%).

\section{CONCLUSIONS}

Mycobacterium tuberculosis is the most common cause of CAP in this study. There is increased incidence of mycoplasma pneumonia in both HIV and non-HIV cohort. PCP, pneumonia is more common in HIV seropositive patients when compared to nonHIV patients.

\section{KEYWORDS}

Human Immunodeficiency Virus (HIV), Community Acquired Pneumonia (CAP), Pneumocystis Pneumonia (PCP), Mycoplasma Pneumonia (M. Pneumonia).

HOW TO CITE THIS ARTICLE: Kumar PVK, Gorantla R, Rachakonda R, et al. Prospective study of pathogens associated with community acquired pneumonia in a mixed population of HIV and non-HIV infected adults. J. Evolution Med. Dent. Sci. 2016;5(16): 778-784, DOI: $10.14260 /$ jemds/2016/181

\section{INTRODUCTION \\ DEFINITION OF PNEUMONIA}

Pneumonia is defined as the accumulation of oedematous fluid and inflammatory cells in the alveoli in response to proliferation of microorganisms in normally sterile lung parenchyma. Community-Acquired Pneumonia (CAP) is defined as an acute infection of the pulmonary parenchyma in a patient who has acquired the infection in the community who has not been hospitalized within 14 days prior to onset of symptoms. ${ }^{1}$ It is most commonly bacterial in nature and is associated with clinical and/or radiological evidence of consolidation of part or parts of one or both lungs. CAP is associated with a considerable burden of disease in most regions of the world. It is one of the most important serious infectious diseases, accounting for a considerable number of hospital admissions with an increasing incidence in many parts of the world and an increasing rate of serious complications.

Financial or Other, Competing Interest: None.

Submission 08-01-2016, Peer Review 07-02-2016,

Acceptance 13-02-2016, Published 24-02-2016.

Corresponding Author:

Dr. P. V. Kalyan Kumar

Associate Professor,

Department of Pulmonary Medicine,

Katuri Medical College \& Hospital, Guntur,

Andhra Pradesh.

E-mail: drpvkalyan@hotmail.com

DOI: $10.14260 /$ jemds $/ 2016 / 181$
As part of the burden of respiratory infections, CAP is well recognised to be a leading cause of death among the infectious diseases. The reason that CAP is so common relates to the very high prevalence of specific risk factors for this infection in patients worldwide. While a myriad of microorganisms may cause CAP, in reality a relatively small number of pathogens predominate, in particular the bacteria.

It is a syndrome characterized clinically by cough with or without sputum production, chest pain, dyspnea, fever, variable physical chest signs consistent with consolidation like impaired percussion note, high pitched bronchial breathing with increased on physical examination and radiological evidence of a new pulmonary infiltrate or opacification (Or consolidation to use a clinical term).

\section{World Scenario}

The spectrum of bacterial pathogens causing CAP in HIVinfected patients is very similar to that in HIV uninfected patients with Streptococcus pneumoniae (Pneumococcus) predominating.

The clinical presentation of CAP in HIV-infected persons, particularly pneumococcal CAP, is similar to that among HIVuninfected patients except that the patients are frequently younger, of the female sex and have a greater frequency of respiratory symptoms. 


\begin{tabular}{|c|c|}
\hline Organism & Clinical Features \\
\hline $\begin{array}{l}\text { Streptococcus } \\
\text { pneumoniae }\end{array}$ & $\begin{array}{l}\text { Increasing age, Cardiovascular } \\
\text { diseases, Acute onset, high fever } \\
\text { and pleuritic chest pain }\end{array}$ \\
\hline $\begin{array}{l}\text { Mycoplasma } \\
\text { pneumoniae }\end{array}$ & $\begin{array}{l}\text { Younger patient, prior antibiotics, } \\
\text { less multisystem involvement, } \\
\text { haemolysis, cold agglutinins, } \\
\text { hepatitis, skin and joint problems }\end{array}$ \\
\hline $\begin{array}{l}\text { Staphylococcus } \\
\text { aureus }\end{array}$ & Recent influenza like illness \\
\hline Legionella & $\begin{array}{l}\text { Young patient, smokers, absence } \\
\text { of comorbidity, neurological } \\
\text { symptoms, evidence of } \\
\text { multisystem involvement }\end{array}$ \\
\hline Chlamydia psittaci & $\begin{array}{l}\text { Long duration of symptoms prior } \\
\text { to admission like headache }\end{array}$ \\
\hline Coxiella burnetii & $\begin{array}{c}\text { Dry cough, high fever, headache, } \\
\text { male, animal exposure }\end{array}$ \\
\hline $\begin{array}{c}\text { Klebsiella } \\
\text { pneumoniae }\end{array}$ & $\begin{array}{l}\text { Low platelet count and leucopenia, } \\
\text { male }\end{array}$ \\
\hline \multicolumn{2}{|c|}{$\begin{array}{c}\text { Table }(A) \text { : Diagnosis of } \\
\text { pathogen based on specific features }\end{array}$} \\
\hline
\end{tabular}

The Microbial Patterns Reported have Differed Considerably. Possible Explanations are:

a. Region studied.

b. Patient population included.

c. Extent of microbiologic testing.

d. Types of microbiologic techniques.

e. Prior antibiotic use, which may mask the identity of a pathogen.

f. (t) Whether or not specialized investigations for atypical organisms were undertaken.

g. Ability of patients to produce sputum samples and whether the samples were of good quality.

h. Scientific and technical ability to pick up new pathogens.

i. The emergence of HIV disease as a major cause of immune dysfunction.

j. Recognition that it is not possible to perform all known microbiological tests due to logistical problems, cost and technical expertise.

\section{Indian Scenario}

Bacteriological profile in Community Acquired Pneumonia (CAP) is different in different countries and changes with time even within the same country. There are a very few and conflicting Indian studies regarding the bacteriological etiology of Community Acquired Pneumonia (CAP). Adding to this agony, there is no credible data from the eastern part of India. Looking at world literatures, microbiological diagnosis could be made in only $40-71 \%$ of cases of CAP even when extensive methods have been used when compared to $>90 \%$ cases in pre-antibiotic era. ${ }^{2}$ The widespread antibiotic (mis) use is probably responsible for decreasing culture rates in CAP. Streptococcus pneumoniae remains the most common organism in CAP in most part of Europe. ${ }^{3}$ United States. ${ }^{4}$ United Kingdom. ${ }^{5}$ and Iraq. ${ }^{6}$

However, their proportion varies in different studies. Viruses are responsible for CAP in as much as $10-36 \%$ of the cases. $^{2}$ In India, the etiological agent of CAP varies with geographical distribution. S. pneumoniae predominates as an etiological agent of CAP in Shimla. ${ }^{7}$ and Delhi. ${ }^{8}$ whereas Pseudomonas aeruginosa predominates in Ludhiana. ${ }^{9}$ Karnataka and Srinagar. 10
In the study from Delhi, S. pneumoniae (35.3\%) was the most common isolate followed by Staphylococcus aureus (23.5\%), Klebsiella pneumoniae (20.5\%) and Haemophilus influenzae $(8.8 \%){ }^{8}$ The study from Shimla showed S. pneumoniae to be the most common cause (35.8\%). ${ }^{7}$ Mycoplasma pneumophila is an important cause, which is often not considered in the Indian setting. Mycoplasma was found to be the etiological agent in $35 \%$ of cases in one study. ${ }^{11}$ There are no large studies that have specifically addressed viruses as the cause of CAP apart from pandemic influenza H1N1 virus. ${ }^{12,2}$

\section{Risk Factors}

Identification of risk factors are equally important in the diagnosis of CAP and some of them are:

Alcohol or drug abuse.

Exposure to people with pneumonia or other respiratory illnesses (Such as tuberculosis).

History of diabetes.

History of chronic obstructive airway disease.

History of smoking.

Occupational risks.

Recent or chronic respiratory infection.

Recent travel.

Environmental factors.

\begin{tabular}{|c|c|}
\hline Organism & Clinical Features \\
\hline Aspiration & $\begin{array}{c}\text { Anaerobes and Gram negative } \\
\text { organisms }\end{array}$ \\
\hline $\begin{array}{c}\text { Alcoholism and } \\
\text { Diabetes }\end{array}$ & $\begin{array}{c}\text { Pneumococcal, Anaerobic and } \\
\text { mixed infections }\end{array}$ \\
\hline Immunosuppression & Legionella \\
\hline Cigarette smoking & Invasive Pneumococcal disease \\
\hline CoPD & $\begin{array}{c}\text { Haemophilus influenzae and } \\
\text { Moraxella catarrhalis }\end{array}$ \\
\hline $\begin{array}{c}\text { Nursing home } \\
\text { residents }\end{array}$ & $\begin{array}{c}\text { Haemophilus influenzae, } \\
\text { Mycoplasma pneumoniae and } \\
\text { Legionella }\end{array}$ \\
\hline Health care worker & Mycobacterium tuberculosis \\
\hline Veterinarian & Coxiella burnetii \\
\hline $\begin{array}{c}\text { Cooling tower } \\
\text { maintenance work }\end{array}$ & Legionella \\
\hline Travel to S.E Asia & $\begin{array}{c}\text { Burkholderia pseudomallei, M. } \\
\text { tuberculosis }\end{array}$ \\
\hline \multicolumn{2}{|c|}{ Table (B): Possible organisms-risk factors } \\
\hline
\end{tabular}

Numerous studies on the etiology of CAP have been published. Most of the studies. ${ }^{13}$ were performed in the developed world. Observed differences in the aetiology of CAP are attributable to the degree of diagnostic testing, the population demographics, seasonal patterns, study duration, study design and more recently the impact of the HIV epidemic. In India, studies of the aetiology of CAP have been scarce and studies from the high burden states of HIV like Andhra Pradesh in India are limited.

\section{Ethical Approval and Patient Consent}

Ethical permission for the study was obtained from the Ethics Committee of Katuri Medical College, NTR Health University. Informed consent was obtained from all subjects.

\section{Patients and Methods}

As per the definition provided by National Joint the Indian Chest Society (ICS)/National College of Chest Physicians (NCCP) (I) recommendations 2012.2 
A total number of 240 cases were included in the study between March 2014 and June 2015, all patients admitted to the hospital with respiratory symptoms of pneumonia and an abnormal chest radiograph of a new infiltrate or consolidation consistent with pneumonia were prospectively studied. Recruitment was performed over 16 months to cover for seasonality and to recruit a reasonable sample size (Though the long duration precluded analysis of seasonality).

\section{INCLUSION AND EXCLUSION CRITERIA}

\section{The following Criteria were used to define a Clinical} Diagnosis of Cap in this Study

1. The presence of any one of the following symptoms:

a) Fever.

b) Cough with or without sputum production.

c) Dyspnoea.

d) Chest pain.

2. Chest radiograph showing the presence of a new infiltrate, opacification or cavitation.

Both criteria 1 and 2 had to be fulfilled.

\section{Exclusion Criteria}

a) Bronchiectasis.

b) Interstitial lung disease.

c) Pulmonary fibrosis.

d) Pneumonia if known to be associated with bronchial carcinoma.

e) Age $<18$ years.

f) Failure to give informed consent.

g) Viral pneumonias.

\section{METHODOLOGY}

Between March 2014 to July 2015, 240 patients admitted with Community Acquired Pneumonia (CAP) were enrolled for study at the Department of Pulmonary Medicine, Katuri Medical College and Hospital, Guntur, Andhra Pradesh, after written informed consent had been obtained from the patient. The study protocol was reviewed and approved by the Ethics Committee of Katuri Medical College, NTR Health University, Andhra Pradesh.

\section{Microbiological Examinations}

Full evaluation included expectorated sputum for cytological screening (Less than 10 epithelial cells and more than 25 polymorphonuclear cells per low power field), Gram's staining of a smear, quantitative sputum culture were done. Sera from patients were used for the antibody detection against atypical organism namely Chlamydia pneumonia, Legionella species and Mycoplasma pneumonia along with the PCR tests. Between 2 and 4 weeks after enrolment, sera were obtained and stored at $80^{\circ} \mathrm{C}$.

\section{Classification of Etiologic Diagnosis}

\section{The Criteria for Etiologic Diagnosis Were}

1. Positive blood culture of bacterial pathogen;

2. A heavy growth of bacterial pathogen $\left[>10 .{ }^{7}\right.$ colonyforming units $(\mathrm{cfu}) / \mathrm{mL}$ ] on sputum culture or a mild growth of bacterial pathogen $\left(>10 .^{6} \mathrm{cfu} / \mathrm{mL}\right)$ in which the Gram-staining of a smear revealed a predominant organism morphologically compatible with the culture result;
3. Four-fold rise in an agglutination test for M. pneumoniae, in an ELISA titer of IgG for C. pneumoniae or in an agglutination test for Legionella species; and

4. Induced sputum revealing Mycobacterium tuberculosis only when M. tuberculosis was regarded to be attributable to CAP.

\section{Statistical Analysis}

The study was prospective study aimed for identifying aetiology of community acquired pneumonia in both HIV and non-HIV patients. Significance of aetiological factors in the cohort of HIV and non-HIV infected were calculated and the corresponding $p$-value were obtained. A $p$ value of $<0.05$ was considered significant.

\section{Clinical and Laboratory Examinations}

Within $24 \mathrm{hr}$. of admission, a physician examined the patients and recorded the findings on standardized case record forms. Diagnostic examinations involved a chest roentgenogram (PA view), complete blood count with differential, blood culture and serum CRP. Hypoxemia, defined as arterial oxygen saturation $<90 \%$ was determined by oximetry on the finger. HIV serostatus was determined for all the patients enrolled using particle agglutination and Western blot. The CD4 and CD8 lymphocyte counts in the peripheral blood were examined by flow cytometry in each patient at the time of enrollment.

The following tests were performed at the time of admission. Chest radiograph performed as soon as possible to confirm diagnosis. Chest X-ray PA and lateral view were done in all patients. Chest radiography showing lobar consolidation was common in typical pneumonia, most commonly in the lower lobes. They are also used to evaluate for complications of pneumonia like empyema, lung abscess, pneumothorax, etc. The chest X-ray were used for suspecting the etiological agent.

\section{The following Features were used for Suspecting the Aetiological Agent}

a. Multilobar involvement (Bacteraemic Pneumococcal).

b. Pleural effusions (Bacteraemic Pneumococcal).

c. Lymphadenopathy (Mycoplasma Infection).

d. Multilobe involvement, cavitation or spontaneous pneumothorax (Staphylococcus Aureus).

e. Upper lobe preponderance may denote Klebsiella pneumonia.

The computed tomography of the thorax were not performed routinely in all patients, but in some cases chest CT (Computed Tomography) revealed pneumonia that was not seen on chest X-ray.

1. Oxygen saturation and where necessary arterial blood gas analysis.

2. Serum urea, creatinine and electrolytes.

3. Liver function tests.

4. Blood Picture: A complete blood count were done in all patients. Increase in white blood cell were common in bacterial infection. Leucopenia in some cases suggested viral pneumonia.

5. ELISA HIV testing was done after appropriate counseling in those patients whose HIV status was unknown.

6. Sputum examination.

The presence of $>25$ white blood cells and $<10$ squamous epithelial cells per high power field suggested that the sputum was appropriate for examination. 
At least 2 sputum samples (Spot and early morning sputum samples) were collected for Ziehl-Neelsen staining, gram staining and fungal staining. For patients who had difficulty producing sputum, sputum was induced by inhalation of aerosolized hypertonic saline generated by a nebulizer. Patients who were unable to produce adequate samples of expectorated sputum were undergone serial sputum induction. Bronchoalveolar lavage were done in patients who were not able produce sputum even after sputum induction. In general, the yields of induced sputum and bronchoalveolar lavage specimens were comparable and induced sputum was safer and less costly.

\section{Sputum Cultures}

Culture of sputum or other lower respiratory tract samples were performed for all patients. Specialized cultures for Mycobacterium species, Legionella species and other atypical organisms were performed in the appropriate clinical circumstance. If the patient was not receiving antibiotics at the time of admission, sputum culture and sensitivity results were obtained. Sputum cultures for Legionella species were done for patients who are legionella urine antigen positive in order to provide isolates for epidemiological typing and comparison with isolates from putative environmental sources.

\section{Blood Cultures}

Samples of blood were collected from all the patients for aerobic and anaerobic cultures. In suspected patients with atypical community acquired pneumonia because of extrapulmonary findings, the following workup was included namely serum phosphorus levels, urinalysis, serum ferritin levels, Creatinine Phosphokinase (CPK) levels, C-reactive Protein (CRP) levels, procalcitonin levels and cold agglutinin titers were done.

\section{Investigations for Typical Pathogens}

Mycoplasma, Chlamydia and Legionella are important atypical etiological agents of pneumonia. Investigations for atypical pathogens were not done routinely. Patients presented with atypical community acquired pneumonia features, the following investigations were done. Culture techniques for Mycoplasma pneumoniae were not only insensitive but also time consuming (2-5 weeks). Serological assays, especially the complement fixation test, were widely used. The sensitivity of these assays varies depending on the timing of collection of the serum sample and the availability of paired serum samples (Collected at an interval of 2-3 weeks). IgM assays were more sensitive, but IgM response may be absent in adults. PCR has been found to be superior to serology for the diagnosis of $\mathrm{M}$. pneumonia, Legionella and C. pneumoniae infection and it was showed to be highly sensitive, specific and rapid.

In our study suspected patients of atypical CAP undergone PCR based tests in respiratory samples for Mycoplasma pneumonia, Legionella and Chlamydia pneumonia were done. In cases complicated by pleural effusions, microbiological staining and culture for bacteria, mycobacteria and fungi were performed and thoracentesis were performed if pleural effusion was significant - Pleural fluid thickness $>10 \mathrm{~mm}$ thickness in lateral decubitus view.

\section{Bronchoscopy}

Bronchoalveolar lavage, protected specimen brushing was done. Urine samples were obtained for Streptococcus pneumoniae and Legionella pneumophila antigen tests.

Overall, the following tests were done for diagnosing specific organisms.

\section{Streptococcus Pneumonia}

Diagnosis were made following pneumococcal urine antigen tests performed for all patients. A rapid testing and reporting service for pneumococcal urine antigen were available in our hospital admitting patients with CAP. Sputum Gram stain and culture were done in all patients to confirm the diagnosis of streptococcus.

\section{Legionnaires Pneumonia}

Diagnosis were done based on investigations for legionella urine antigen performed for all patients with specific risk factors and culture of legionella done on respiratory secretions including sputum, invasive respiratory samples obtained by bronchoscopy. For all patients who were legionella urine antigen positive, respiratory specimens such as sputum were done for legionella culture.

\section{Mycoplasma Pneumonia}

PCR of respiratory tract samples, such as sputum were done for the diagnosis of mycoplasma pneumonia. In absence of a sputum or lower respiratory tract sample and where mycoplasma pneumonia is suspected on clinical and epidemiological grounds, a throat swab for mycoplasma pneumonia.

\section{Chlamydia Pneumonia}

Chlamydia antigen and/or PCR detection tests were done for invasive respiratory samples from patients with strong suspicion of chlamydia infection. The complement fixation test remains the most suitable and practical serological assay for routine diagnosis of respiratory chlamydia infections.

\section{Pneumocystis Jirovecii (PCP)}

PCP was diagnosed by using a microscope to identify P. Jirovecii organisms in a sample of lung fluid or tissue. The sample was usually induced sputum or Bronchoalveolar Lavage (BAL) material. More invasive diagnostic techniques like transbronchial biopsy or open-lung biopsy were done to diagnose the suspected case of pneumocystis jirovecii pneumonia.

\section{RESULTS}

A total of 240 patients comprising 151 females (63\%) and 89 males (47\%) were admitted with CAP over a 16-month period. The patient's ages ranged from 18 to 82 years with a mean of 33 years. The average duration of symptoms was 10 days with a range of 1-21 days.

Ninety two patients were HIV seropositive $38 \%$ of the total number of patient) while $123(51 \%)$ patients were HIV negative and 25 (11\%) patients declined testing. The CD4 count was performed in 81 HIV patients. Seventy two percent had CD 4 counts less than 200 cells/mm3. The mean CD4 count was 153 with a range of $0-1223$ cells per cubic millimeter of blood. 


\section{Etiology}

The etiology of the pneumonia was identified in 129 patients (53\%) and 1 patients had bronchial carcinoma. In total of 150 pathogens were isolated. The commonest pathogen were Mycobacterium tuberculosis (41\%) followed by Mycoplasma pneumoniae (29\%), Streptococcus pneumonia (26\%) and Pneumocystis pneumonia (9\%) in both HIV and non-HIV group (Fig. 1). Two patients, both HIV infected had Cryptococcus neoformans pneumonia. Two patients had chicken pox pneumonia. One was HIV seropositive and the other patient had chronic renal failure and was HIV seronegative (Table 1).

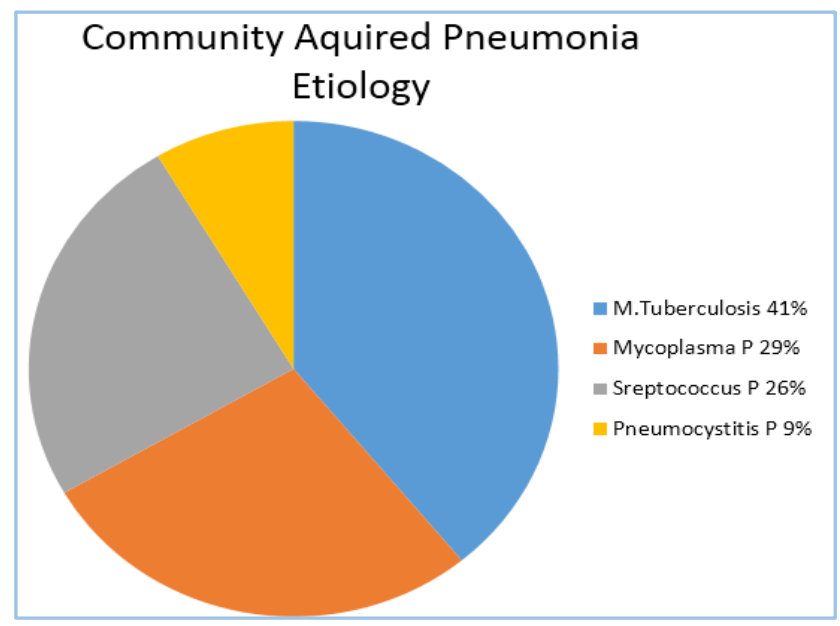

Fig. 1: Etiology of Community Acquired Pneumonia

Differences in Etiology between HIV and Non-HIV infected Mycobacterium tuberculosis was the most common cause of pneumonia in our study. The incidence of M. Tuberculosis was more common in HIV seropositive (Fig. 2) patients when compared to HIV seronegative patients $(38 \%$ vs. $9 \%$, $\mathrm{p}=<0.001$ ). In our study overall incidence of mycoplasma pneumonia was high and is more common in HIV patients (31\%) when compared to non-HIV patients (31\% vs. 5\%, $\mathrm{p}=<0.001)$. PCP pneumonia was more in HIV than in non-HIV group (Fig. 3). Even though streptococcus pneumonia was the most common cause of pneumonia in non-HIV group, but there is no statistical significance when compared to HIV cohort (12\% vs. $9 \%)$.

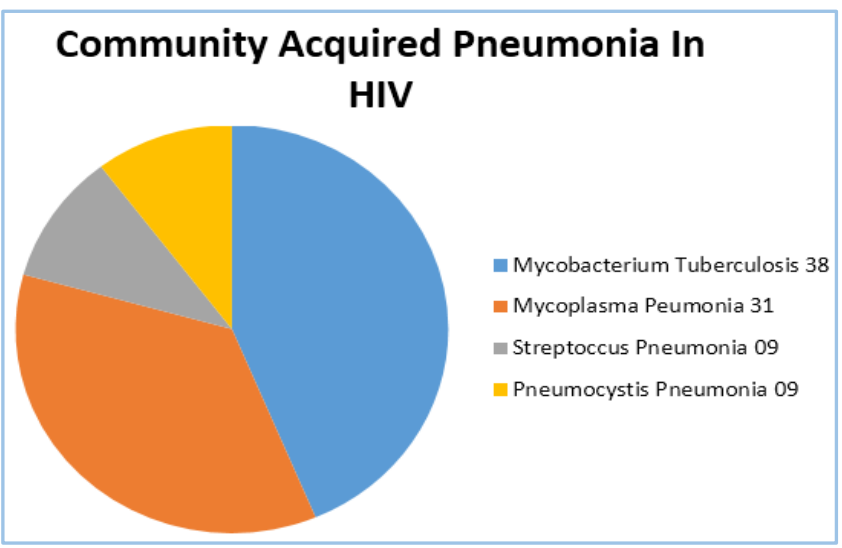

Fig. 2: Community Acquired Pneumonia in HIV patients

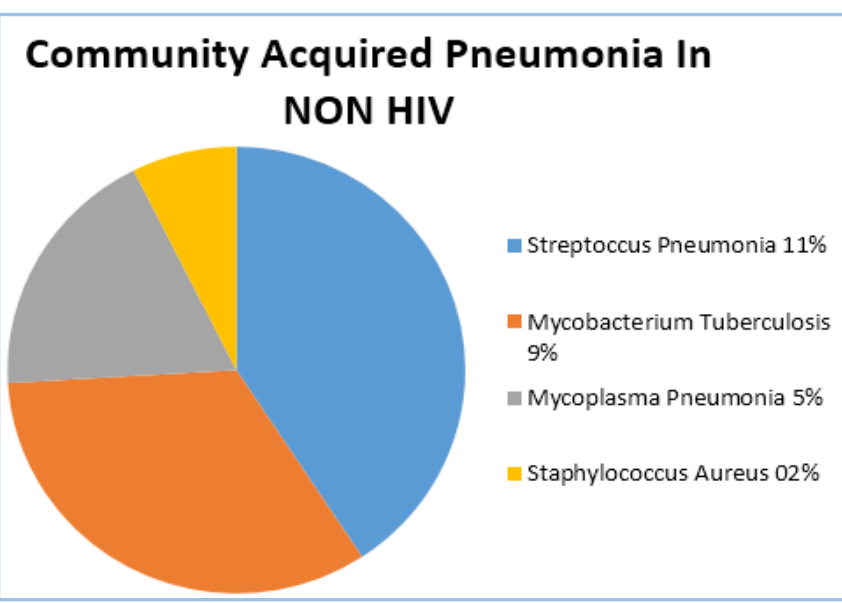

Fig. 3: Community Acquired

Pneumonia in Non-HIV patients

\begin{tabular}{|c|c|c|c|c|c|}
\hline Organism & $\begin{array}{c}\text { HIV } \\
+\end{array}$ & HIV- & $\begin{array}{c}\text { Unknown } \\
\text { Status }\end{array}$ & $\begin{array}{c}\text { Total } \\
\text { Number }\end{array}$ & \% \\
\hline $\begin{array}{c}\text { Mycobacterium } \\
\text { tuberculosis }\end{array}$ & 35 & $\begin{array}{c}12 \\
\mathrm{P}=<0.00 \\
1\end{array}$ & 6 & 53 & 41.0 \\
\hline $\begin{array}{c}\text { Streptococcus } \\
\text { pneumoniae }\end{array}$ & 12 & 15 & 7 & 34 & 26.3 \\
\hline $\begin{array}{c}\text { Staphylococcus } \\
\text { aureus }\end{array}$ & 04 & 03 & 1 & 08 & 06.2 \\
\hline $\begin{array}{c}\text { Haemophilus } \\
\text { influenzae }\end{array}$ & 03 & 02 & 0 & 05 & 03.8 \\
\hline $\begin{array}{c}\text { Pseudomonas } \\
\text { aeruginosa }\end{array}$ & 02 & 04 & 0 & 06 & 04.6 \\
\hline Escherichia coli & 02 & 02 & 0 & 04 & 03.1 \\
\hline $\begin{array}{c}\text { Klebsiella } \\
\text { pneumoniae }\end{array}$ & 02 & 01 & 0 & 03 & 02.3 \\
\hline $\begin{array}{c}\text { Gram negative } \\
\text { bacilli }\end{array}$ & 02 & 01 & 0 & 03 & 02.3 \\
\hline $\begin{array}{c}\text { Serratia } \\
\text { marcescens }\end{array}$ & 02 & 01 & 0 & 03 & 02.3 \\
\hline Bacillus specie & 01 & 01 & 0 & 02 & 01.5 \\
\hline $\begin{array}{c}\text { Legionella } \\
\text { pneumophila }\end{array}$ & 01 & 01 & 0 & 02 & 01.5 \\
\hline $\begin{array}{c}\text { Cryptococcus } \\
\text { neoformans }\end{array}$ & 02 & 00 & 0 & 02 & 01.5 \\
\hline Chickenpox & 01 & 01 & 0 & 02 & 01.5 \\
\hline $\begin{array}{c}\text { Carcinoma of } \\
\text { bronchus }\end{array}$ & 00 & 01 & 0 & 01 & 00.7 \\
\hline Anaerobes & 01 & 00 & 0 & 01 & 00.7 \\
\hline $\begin{array}{c}\text { Candida } \\
\text { albicans }\end{array}$ & 01 & 00 & 0 & 01 & 00.7 \\
\hline $\begin{array}{c}\text { Moraxella } \\
\text { catarrhalis }\end{array}$ & 01 & 00 & 0 & 01 & 00.7 \\
\hline $\begin{array}{c}\text { with Community Acquired Pneumonia } \\
\text { (1) Typical Organisms associated }\end{array}$ & \\
\hline
\end{tabular}

\section{Other Pathogens}

Pseudomonas aeruginosa was more prevalent in the HIV negative group than in the non-HIV infected cohort ( 4 cases vs. 2 cases; $p=0.0 I$ ). No differences were noted in the prevalence of the other pathogens isolated, namely streptococcus pneumonia (12 vs. 15$)$ staphylococcus aureus (4 vs. 3 ); haemophilus influenzae (3 vs. 2); E. coli (2 vs. 2) and remaining other pathogens.

\section{HIV Infection and A Typical Pathogens}

Eight of the 11 patients $(72.7 \%)$ with Chlamydia pneumoniae infection were HIV seropositive. Two had negative serology and one had declined to have the test done. Twenty-nine of the 38 cases (76.3\%) of Mycoplasma pneumoniae infection were HIV infected, seven were negative and 2 declined (Table 2). 
This study has shown an incidence of $11 \%$ in the frequency of PCP in a cohort of HIV infected patients presenting with CAP (Table 3). None of the HIV seronegative subjects had PCP. PCP should be considered regardless of whether the presentation is typical or not as only three of the 9 patients had clinical and radiological features suggestive of PCP.

\begin{tabular}{|c|c|c|c|c|c|}
\hline $\begin{array}{c}\text { Atypical } \\
\text { Organisms }\end{array}$ & $\begin{array}{c}\text { HIV } \\
+\end{array}$ & HIV- & $\begin{array}{c}\text { Unknown } \\
\text { Status }\end{array}$ & $\begin{array}{c}\text { Total } \\
\text { Number }\end{array}$ & \% \\
\hline $\begin{array}{c}\text { Mycoplasma } \\
\text { pneumoniae }\end{array}$ & 29 & 07 & 02 & 38 & 29.4 \\
\hline $\begin{array}{c}\text { Chlamydia } \\
\text { nneumonia }\end{array}$ & 08 & 02 & 01 & 11 & 08.5 \\
\hline $\begin{array}{c}\text { Legionella } \\
\text { pneumophila }\end{array}$ & 01 & 01 & 00 & 02 & 01.5 \\
\hline \multicolumn{7}{|c|}{ Table 2: Atypical Organisms associated } \\
with Community Acquired Pneumonia \\
\hline
\end{tabular}

\begin{tabular}{|c|c|c|c|c|c|}
\hline $\begin{array}{c}\text { Pneumocystis } \\
\text { Pneumonia }\end{array}$ & HIV+ & HIV- & $\begin{array}{c}\text { Unknown } \\
\text { Status }\end{array}$ & $\begin{array}{c}\text { Total } \\
\text { Number }\end{array}$ & $\%$ \\
\hline \multicolumn{6}{|c|}{ Table 3: Pneumocystis pneumonia } \\
\hline \multicolumn{7}{|c|}{ in Community Acquired Pneumonia } \\
\hline
\end{tabular}

\section{DISCUSSION}

Mycobacterium tuberculosis was the commonest cause of CAP in the 53 patients studied. It comprised $41 \%$ of isolates. The presentation of Mycobacterium tuberculosis, traditionally a cause of chronic pneumonia, as acute CAP and in such a high proportion is cause for concern. Most studies of the studies that were done earlier excluded patients who are HIV seropositive or those with Mycobacterium tuberculosis as the etiology of community acquired pneumonia.

Tuberculosis, a disease caused by the bacillus M. tuberculosis affects 9.6 million individuals by 2014 and is responsible for the death of 1.5 million individuals across the world annually. ${ }^{14}$ However, the disease can present as an acute pneumonia masquerading as a Community Acquired Pneumonia (CAP). The incidence of TB being diagnosed among patients presenting with clinical and radiological signs of a CAP has varied across series and can be as high as 35 percent of microbiologically confirmed pneumonias, the incidence being higher in the HIV-positive subgroup of patients. Guntur district, which forms part of the AP state capital region tops the list of HIV positive cases in the state. The district also had the dubious distinction of being the "HIV capital" in undivided Andhra Pradesh in the last two years.

The acute presentation of TB can result from the primary infection, progressive primary disease, reactivation of latent TB or atelectasis caused by the effects of compression or rupture of enlarged tuberculous lymph nodes. TB is seldom thought of when the patient presents as an acute pneumonia gets treated with antibiotics, a variety of which are known to have antituberculous effects, resulting in transient improvement of the clinical picture. The most potent of the antituberculous antibiotics are fluoroquinolones, recommended in the guidelines as one of the first-line drug options in the management of hospitalized patients with community acquired pneumonia. The empiric use of antibiotics in the absence of an index of suspicion for TB results in delays in diagnosis and institution of antituberculous therapy and such delays are known to cause increased morbidity and mortality and increase the risk of forward transmission.
The second and equally worrisome result of the use of fluoroquinolones in the management of tuberculosis misdiagnosed as community acquired pneumonia is the acquisition of resistance to fluoroquinolones during the period that the bacillary load is exposed to monotherapy with the drug. A course of fluoroquinolone monotherapy for as short a duration as 13 days has been found to select resistant mutants. Fluoroquinolones are one of the most potent drugs in the treatment of multidrug resistant $\mathrm{TB}$ and propagation of resistance would accelerate the selection of XDR- and pre-XDR mutants.

There are clues that should be looked for while assessing the probability of tuberculosis in any patient diagnosed with a community acquired pneumonia. Chronicity of symptoms, presence of pleural effusions, unsatisfactory response to standard empiric antibiotics that cover the commonest pathogens or a transient improvement with the use of fluoroquinolones followed by deterioration on cessation of therapy, a history of prior tuberculosis or close contact with a patient suffering from tuberculosis, a normal leucocyte count, weakly gram-positive or gram-neutral rods on sputum smear examination should alert the physician to the possibility of tuberculosis.

In addition to these clues, underlying conditions that predispose to infection and increase the risk of reactivation of latent TB such as diabetes, renal failure, gastrectomy and immunosupressed conditions (HIV, corticosteroid therapy, tumor necrosis factor-alpha inhibitor therapy, posttransplantation state) should be specifically looked for and an increased index of suspicion for TB is warranted in the presence of any of such predisposing factors. It is especially important to strongly suspect TB in the differential diagnosis of CAP in countries that are endemic for TB like India and among immigrants from such countries.

\section{Mycoplasma Pneumonia}

M. pneumoniae causes mainly infection of the upper respiratory tract (Tracheitis, bronchitis) and in $3-10 \%$ of cases pneumonia. Rare neurological symptoms such as meningitis and Guillain-Barre syndrome can be observed. The bacterium is spread by respiratory droplets and direct contact with an infected person. The disease occurs in all age groups, but is most common among children aged 7-16 years and young adults aged 17-25 years. Presumably due to lack of lifelong protective immunity and changes in circulating $\mathrm{M}$. pneumoniae strains, epidemics typically occur in 3-5 year intervals with seasonal peaks in autumn and winter.

Most of the available data concerning the occurrence of Mycoplasma pneumoniae infections have come from studies performed in the United States, Europe and Japan. These studies are basically seroprevalence investigations that indicate the presence of Mycoplasma pneumoniae antibodies and suggest that populations in these regions have had infections due to this organism. Much of what we know about rates of the infections caused by the organism comes from population based studies relying primarily on serological measurements. In the past diagnosis of infection by this organism was usually based on serology, because growth in culture is slow and insensitive. Therefore, nucleic acid amplification techniques have been introduced.

PCR of fragments of the P1 gene or the 16S rRNA gene were shown to be considerably more sensitive than culture for the detection of M. pneumonia. 
Developed countries like USA where M. pneumoniae is responsible for more than one lakh hospitalizations each year. The non-availability of reliable, rapid diagnostic techniques as well as the lack of clinical awareness is the probable reason for sparse studies from India on the organism. There are a few studies from the North India and a few from the South India, but these do not provide any statistical data.

This study is hence an attempt to find out the prevalence of M. pneumoniae infections in this part of the country using culture as well as PCR as the methods of analysis. In the current study two different methods namely culture and PCR are used for the detection of Mycoplasma pneumoniae in the clinical samples. Difference in the prevalence of $M$. pneumoniae infections among various workers in India and other countries could be due to various reasons as follows:

1. The methodology of laboratory procedures, patient study group, age and sex distribution and the predisposing factors.

2. The spread of M. pneumoniae infections in the community is by means of droplet infections and fomites.

3. Viability and spread of M. pneumoniae from one patient to another may depend on environmental and climatic conditions like temperature, humidity and season.

4. Lastly the health education of the patients regarding prevention of the disease and implementation of aseptic procedures by the health care workers and doctors may also be responsible for the variation.

As a result no data is available regarding regular diagnosis and treatment of M. pneumoniae infections. For the same reason, very few studies have been done in India on M. pneumoniae. Hence, this study gives an idea of the current scenario of $M$. pneumoniae infections in this part of the country. The laboratory tests set up during this research work will help the diagnosis of M. pneumoniae infections in our hospital for proper treatment and management. This will help to reduce the morbidity and mortality due to M. pneumoniae infections.

\section{CONCLUSION}

This study highlights the fact that pulmonary tuberculosis, though commonly a disease with a sub-acute smouldering presentation can occasionally masquerade as an acute community acquired pneumonia and should be entertained as a possible differential diagnosis in any patient with CAP. Fluoroquinolones, despite being advocated in guidelines should be discouraged in the treatment of CAP, especially in areas endemic for $\mathrm{TB}$, not only because they delay the diagnosis of the disease, but also because they cause the selection of resistant mutants in cases where the CAP is due to TB. TB presenting as an acute pneumonia with respiratory failure is treated in the same manner as pulmonary TB presenting in other forms. This study gives an idea of the current scenario of M. pneumoniae infections in this part of the country.

\section{REFERENCES}

1. Bartlett J, Dowell S, Mandell L, et al. Practice guidelines for the management of community acquired pneumonia in adults. Clin Infect Dis 2000;31:347-382.

2. Gupta D, Agarwal R, Aggarwal AN, et al. Guidelines for diagnosis and management of community- and hospitalacquired pneumonia in adults: joint ICS/NCCP (I) recommendations. Lung India 2012;29:S27-62.

3. Lode HM. Managing community-acquired pneumonia: a European perspective. Respir Med 2007;101:1864-73.

4. BartlettJG, Mundy LM. Community-acquired pneumonia. N Engl J Med 1995;333:1618-24.

5. Howard LS, Sillis M, Pasteur MC, et al. Microbiological profile of community-acquired pneumonia in adults over the last 20 years. J Infect 2005;50:107-13.

6. Al-Ghizawi GJ, Al-Sulami AA, Al-Taher SS. Profile of community- and hospital-acquired pneumonia cases admitted to Basra General Hospital, Iraq. East Mediterr Health J 2007;13:230-42.

7. Bansal S, Kashyap S, Pal LS, et al. Clinical and bacteriological profile of community acquired pneumonia in Shimla, Himachal Pradesh. Indian J Chest Dis Allied Sci 2004; 46:17-22.

8. Capoor MR, Nair D, Aggarwal P, et al. Rapid diagnosis of community-acquired pneumonia using the BacT/Alert 3D system. Braz J Infect Dis 2006;10:352-6.

9. Oberoi A, Agarwal A. Bacteriological profile, serology and antibiotic sensitivity pattern of microorganisms from community acquired pneumonia. JK Sci 2006;8:79-82.

10. Shah BA, Singh G, Naik MA, et al. Bacteriological and clinical profile of community acquired pneumonia in hospitalized patients. Lung India 2010;27:54-7.

11. Javed S, Chaudhry R, Passi K, et al. Serodiagnosis of Legionella infection in community acquired pneumonia. Indian J Med Res 2010;131:92-6.

12. Dey AB, Chaudhry R, Kumar P, et al. Mycoplasma pneumoniae and community-acquired pneumonia. Natl Med J India 2000;13:66-70.

13. Kara W Chew, Irene H Yen, Jonathan Z Li, et al. Predictors of Pneumonia severity in HIV-infected adults admitted to an Urban Public Hospital. AIDS Patient Care and STDS 2011 May;25(5):273-277.

14. World Health Organization. Global Tuberculosis Control: World Tuberculosis Report 2015. World Health Organization, Geneva (2015). 